\title{
Acculturation and overweight-related behaviors among Hispanic immigrants to the US: the National Longitudinal Study of Adolescent Health
}

\author{
Penny Gordon-Larsen ${ }^{\mathrm{a}, \mathrm{b}, *}$, Kathleen Mullan Harris ${ }^{\mathrm{a}, \mathrm{c}}$, Dianne S. Ward ${ }^{\mathrm{b}}$, \\ Barry M. Popkin ${ }^{\mathrm{a}, \mathrm{b}}$ \\ ${ }^{a}$ Carolina Population Center, University of North Carolina at Chapel Hill, 123 West Franklin St., Chapel Hill, NC 27516-3997, USA \\ ${ }^{\mathrm{b}}$ Department of Nutrition, Schools of Public Health and Medicine, University of North Carolina at Chapel Hill, Chapel Hill, \\ NC 27516, USA \\ ${ }^{c}$ Department of Sociology, University of North Carolina at Chapel Hill, 123 west Franklin St. Chapel Hill, NC 27516, USA
}

\begin{abstract}
Little is known about the factors underlying the striking increase in overweight occurring between first and second generation US immigrants. Using data from the National Longitudinal Study of Adolescent Health, this study addressed two goals. First, we determined which measures of acculturation (defined as the acquisition of dominant cultural norms by members of a non-dominant group) were important. Second, we determined how the acculturation process affected differences in overweight and its proximate determinants (e.g., physical activity, diet, and smoking) as immigrants acculturated to American society. In addition, we sought to elucidate the role of underlying structural factors (e.g., family income and crime) and acculturation factors (e.g., language spoken at home and proportion of foreign-born neighbors) in generation differences in overweight. Results showed clear structural and acculturation differences between foreign and US-born immigrants to the US. Foreign-born immigrants were more likely to have lower family income and maternal education, and to live in areas of higher immigrant density and greater linguistic isolation. In addition, results suggested rapid acculturation of overweight-related behaviors, such as diet, smoking, and inactivity, in US-born relative to foreign-born immigrants. Multivariate analysis indicated that longer US residence was associated with increased overweight among Puerto Ricans and Cubans. Predicted probabilities showed that controlling for acculturation and proximate factors increased overweight among foreign-born adolescents, but had minimal impact for US-born adolescents. Thus, without the beneficial pattern of: acculturation factors, diet, and physical activity, first generation Hispanic adolescents would have higher overweight prevalence. We found important generation differences in structural, acculturation, and proximate overweight determinants. These lifestyle differences between foreign- and US-born Hispanic adolescent immigrants are likely to underlie the striking increase in overweight prevalence between first and subsequent generation of US residence.
\end{abstract}

(C) 2003 Elsevier Science Ltd. All rights reserved.

Keywords: Acculturation; Physical activity; Diet; Smoking; Environment/context; US

\section{Introduction}

First and second generation immigrants comprise the

*Corresponding author. Tel.: +919-843-9966; fax: +919966-9159. fastest growing segment of the US child population, including approximately $60 \%$ of all Hispanic-American

E-mail address: gordon_larsen@unc.edu (P. Gordon-Larsen). children (Zhou, 1997). Language barriers, low socioeconomic status (SES), cultural differences, and limited 
health care access (Wolfe, 1994) place immigrants at risk for low SES (Gordon, 1964; Lieberson, 1980), diminished health and well being. These difficulties decrease with each generation (Hirschman, 1996). However, immigrant populations are diverse and there are paradoxes in health by acculturation across populations (Park, 1950; Portes, 1996). For some populations and some health outcomes, first generation immigrants have better health despite lower SES [e.g., low birth weight, perinatal mortality (Guendelman, 1988; Guendelman \& Abrams, 1995; Scribner \& Dwyer, 1989; Scribner, 1996; Harris, 1998)] than the native population. Where this paradox is shown, the relative advantage declines with length of residence in the US (Committee on the Health and Adjustment of Immigrant Children and Families, 1998).

Over time, immigrant children adopt American behavioral norms for health status and risk (Harris, 1999a, b). However, reinforcement of native ethnic group values and norms can slow the acculturation process (Harris, 1999a,b). While these studies offer insights into the role that acculturation might play in enhancing health inequality, they do not identify potential mechanisms. Despite difficulties faced by US immigrant children, little research has examined the effects of immigration on health status (e.g., Harris, 1999a, b; Hernandez, 1993; Jasso \& Rosenzweig, 1990; Lieberson, 1980; Portes \& Zhou, 1993).

\section{Immigrants and patterns of overweight}

Adolescent obesity has important health, social, and economic consequences and is a major antecedent of adult obesity (e.g., Dietz, 1994; Serdula et al., 1993; Siervogel, Roche, Guo, Mukherjee, \& Chumlea, 1991). The acculturation process is related to a striking increase in obesity between first and second generation Hispanic (Popkin \& Udry, 1998) and Mexican-American (Mendoza \& Dixon, 1999) adolescents. Furthermore, CVD and CVD-related risk factors are higher in US-born relative to foreign-born immigrants and particularly higher in immigrants who are more acculturated [e.g., in Mexican-Americans (Sundquist \& Winkleby, 1999)].

Low physical activity levels and high inactivity, important biological determinants of obesity (Gortmaker, Sobal, Peterson, Colditz, \& Dietz, 1996; Epstein et al., 1995; Epstein, Saelens, Myers, \& Vito, 1997; USDHHS, 1996) that track over the lifecycle (Raitakari et al., 1994), tend to be high in Hispanic-Americans (Gordon-Larsen, McMurray, \& Popkin, 1999). Although there is minimal dietary data on Hispanic immigrants (Hernandez \& Charney, 1998), researchers have generally found healthier dietary intakes among foreign- versus US-born Hispanics (Schaffer, Velie, Shaw, \& Todoroff, 1998; Guendelman \& Abrams,
1995; Winkleby, Albright, Howard-Pitney, Lin, \& Fortmann, 1994).

Although there is limited literature on this topic, structural factors, such as income and education may determine level of access to an American lifestyle, with decreased physical activity opportunities and increased availability of high-fat energy-dense foods, and thus higher obesity among low SES populations. Where immigrants settle has substantial implication for dietary and activity patterns, given availability of markets that supply foreign versus American goods and services. Furthermore, the contextual setting to which immigrants acculturate will have considerable impact on socioeconomic attainment (Portes \& Zhou, 1993), particularly given the spatial concentration of affluence and poverty (Massey, 1996).

The objective of our study was to explore mechanisms that may explain the overweight differential across immigrant generations among three large subpopulations of Hispanic (Mexican, Puerto Rican, and Cuban) youth in the US. We define acculturation as the acquisition of dominant cultural norms by members of a non-dominant group. We aim to understand how the acculturation process affects differences in overweight and its proximate determinants as immigrants acculturate to American society. In addition, we aim to understand the role of underlying structural factors in generation differences in overweight prevalence.

\section{Data}

Survey design. The study population included over 20,000 adolescents enrolled in the National Longitudinal Study of Adolescent Health (Add Health), a longitudinal, nationally representative, school-based study of US adolescents in grades 7-12, supplemented with minority special samples and collected under protocols approved by the Institutional Review Board of the University of North Carolina-Chapel Hill. The survey design and sampling frame have been described in detail elsewhere (Popkin \& Udry, 1998; Gordon-Larsen et al., 1999; Harris, 1999a, b).

Our final analysis sample included 8613 adolescents (Table 1) from four ethnic groups (Non-Hispanic Whites $(N=6727), \quad$ Mexican/Chicanos $(N=1151)$, Puerto Ricans $(N=398)$, and Cubans $(N=337)$ from Waves I (1995) and II (1996) of Add Health.

\section{Dependent variable}

Overweight. Height and weight were measured in Wave II during in-home surveys; body mass index (BMI; $\mathrm{kg} / \mathrm{m}^{2}$ ) was calculated as a measure of adolescent adiposity (Himes \& Dietz, 1994; WHO, 1995). Overweight status was defined as a $\mathrm{BMI} \geqslant 85$ th percentile of 
Table 1

Sample Characteristics

\begin{tabular}{|c|c|c|}
\hline Characteristic & Percentage or mean (SE) & Number \\
\hline \multicolumn{3}{|l|}{ Age } \\
\hline Mean age & $15.93(0.13)$ & 8613 \\
\hline \multicolumn{3}{|l|}{ Sex } \\
\hline Male & 50.5 & 4267 \\
\hline Female & 49.5 & 4346 \\
\hline \multicolumn{3}{|l|}{ Ethnicity } \\
\hline White (ref) & 78.1 & 6727 \\
\hline Mexican & 13.4 & 1151 \\
\hline Puerto Rican & 4.6 & 398 \\
\hline Cuban & 3.9 & 337 \\
\hline \multicolumn{3}{|l|}{ Generation } \\
\hline 1st generation & 4.5 & 392 \\
\hline 2nd plus generation & 95.5 & 8221 \\
\hline \multicolumn{3}{|l|}{ Ethnicity and generation } \\
\hline \multicolumn{3}{|l|}{ White } \\
\hline 1st generation & 0.6 & 44 \\
\hline 2nd plus generation & 99.4 & 6683 \\
\hline \multicolumn{3}{|l|}{ Mexican } \\
\hline 1st generation & 16.3 & 187 \\
\hline 2nd plus generation & 83.8 & 964 \\
\hline \multicolumn{3}{|l|}{ Puerto Rican } \\
\hline 1st generation & 5.8 & 23 \\
\hline 2nd plus generation & 94.2 & 375 \\
\hline \multicolumn{3}{|l|}{ Cuban } \\
\hline 1st generation & 41.0 & 138 \\
\hline 2nd plus generation & 59.1 & 199 \\
\hline
\end{tabular}

age and sex-specific cut-points from the $2000 \mathrm{CDC} /$ NCHS growth charts (Centers for Disease Control and Prevention, 2000). Age- and sex-specific reference data, rather than cutpoints, are necessary during the adolescent growth period.

\section{Independent variables}

Acculturation variables. Acculturation data were collected from adolescents and parents in the in-home surveys. Immigrant generation was based on questions about adolescent's and parents' place of birth. Generation one includes children not born in the US and Generation two or greater includes children born in the US but with at least one parent who is foreign-born or children who were born in the US to US-born parents. In general, second generation adolescents are closer to third and greater generation than first generation adolescents on health-related measures examined here (Harris, 1999a, b). Due to their smaller sample size, we did not retain generation two adolescents as a separate group. The analysis sample included a substantial percentage of first generation, or foreign-born Hispanic adolescents (e.g., $16 \%$ of Mexicans, $6 \%$ of Puerto Ricans, and $41 \%$ of Cubans).
Acculturation data were also taken from the Add Health contextual database, which links geocoded respondent addresses and census areas. We used data from the 1990 Census of Population and Housing by census block group on percent of Hispanic population, proportion of the population that is foreign-born, dispersion in ethnic population, and proportion of households that are linguistically isolated (a measure of non-English speakers in the household). From selfreports we used reported language spoken at home (English or non-English) and years the respondent has lived in the US $(0-5 ; 6-10)$.

Proximate determinants. Physical activity and inactivity patterns are important determinants of overweight and potential mediators of immigrant generation, as well as important avenues for treating and preventing overweight (Epstein et al., 1995; Epstein, Saelens, Myers, \& Vito, 1997; USDHHS, 1996). Physical activity and inactivity data were collected using a standard set of recall questions over a 7-day period that are relevant for epidemiologic research (Andersen, Crespo, Bartlett, Cheskin, \& Pratt, 1998; Baranowski, 1988; Pate, Heath, Dowda, \& Trost, 1996; Sallis, Buono, Roby, Micale, \& Nelson, 1993). Activity is reported in bouts per week. Moderate to vigorous physical activities included skating and cycling, exercise and active sports, with an estimated energy cost of 5-8 METs (metabolic equivalent values; $1 \mathrm{MET}=3.5 \mathrm{ml} \mathrm{O}_{2} / \mathrm{kg}$ body weight $/ \mathrm{min}$ ). Low intensity activity (2-3 METs) included house cleaning, hobbies, and "hanging out with friends". We used two separate categories of inactivity, TV/video viewing (1 MET) and computer/video game use (1 MET).

Baseline and 1-yr change (Waves I-II) in physical activity/inactivity were monitored. Wave I baseline measures included: hours/week of $\mathrm{TV} /$ video viewing ( $>26 \mathrm{~h} / \mathrm{wk})$, hours/week of computer/video game use ( $>1 \mathrm{~h} / \mathrm{wk}$ ), weekly bouts of moderate-vigorous physical activity ( $>4$ bouts/wk) and bouts/week of low intensity physical activity ( $>5$ bouts/wk). One-year change (Waves II-I) measures included: TV/video viewing $(\geqslant 7 \mathrm{~h} / \mathrm{wk})$, computer/video game use $(\geqslant 1 \mathrm{~h} / \mathrm{wk})$, moderate-vigorous physical activity ( $\geqslant 1$ bout $/ \mathrm{wk}$ ), and low intensity physical activity ( $\geqslant 1$ bout/wk).

Dietary data were collected in Wave II. We used specific foods with relevance for acculturation (e.g., dairy, beans, rice, and fast foods) including meal patterns (Siega-Riz \& Popkin, 2001). Respondents reported whether or not they ate a given food "yesterday" as part of a meal or snack. Although quantities of food consumed were not collected, data were sufficient for descriptive analysis of dietary patterns by immigrant generation and for examination of the contribution of diet to overweight. Diet variables included consumption of: milk, cheese, ready-to-eat cereal, rice, beans, pizza, lowfat foods (selects low fat 
options of sweets, dairy, or meat), fruit ( $\geqslant 2$ times/wk), vegetables ( $\geqslant 2$ times/wk), fast foods ( $\geqslant 2$ times/wk), breakfast ( 7 days/wk, versus $0-6$ days/wk), lunch ( 7 days/wk versus $0-6$ days/wk), and dinner (7 days/wk versus $0-6$ days/wk).

Smoking is a well-known determinant of overweight. French, Perry, Leon, \& Fulkerson (1994) and French, Story, Downes, Resnick, \& Blum (1995) showed a relationship of dieting behaviors and smoking, suggesting a clustering of risk factors related to body weight. Smoking is viewed as a weight control method (Camp, Klesges, \& Relyea, 1993). Smoking cessation has long been associated with weight gain in adults (Flegal, Troiano, Pamuk, Kuczmarski, \& Campbell, 1995). Whether or not an adolescent was a current smoker was thus included in the models of overweight.

Structural variables. We included structural factors to control for differences in social structure by generation and ethnicity. Structural characteristics included: total family income (high, low, ref: medium), maternal education (college educated or greater, less than high school, ref: high school-some college), region (Northeast, South, Midwest, ref: West), proportion of households at the Census block level within an urbanized area, total reported incidents of serious crime per 100,000 at the county level [a spatial contextual variable (low: 0 4796; ref: 4800-7139, high: 7170-16,855)].

Key control variables. We also included key control variables shown to have substantial impact on overweight. These variables included: gender (male, ref: female), age $(16,17 \mathrm{yr}, 18+\mathrm{yr}$, ref: $12-15 \mathrm{yr})$, and current pregnancy status (yes, no).

\section{Analysis plan}

We examined differentials in structural characteristics and acculturation by generation for Mexican, Puerto Rican, and Cuban youth. Then we documented differentials in overweight status and its proximate determinants (e.g., physical activity, inactivity, diet, and smoking) across generation in our three ethnic groups.

Logistic regression models of overweight were used to investigate ethnicity and generation interactions in relation to acculturation, sociodemographic, contextual, physical activity, and diet correlates. We asked the question: Does the ethnicity effect on overweight status vary by generation? Although our focus was on the Hispanic groups, we included all youth in our models (Whites as the reference group) and specified first generation, ethnicity, and a series of generation and ethnicity interaction terms. We structured the models in this manner to facilitate within-ethnicity comparisons by generation.

Significance of interaction terms was tested using a $\chi^{2}$ test of the difference in log likelihoods between a model with and without the interaction terms. Model fit was significantly improved with interaction terms $\left(\chi^{2}=16.44\right.$; Prob $\left.>\chi^{2}=0.0057\right)$. Overweight prevalence varied significantly by generation for Mexican and Cuban youth (see Appendix).

Statistical analyses were carried out using STATA (Stata Corp, 1999). All models were weighted for national representation and standard errors were corrected for survey design effects of multiple stages of cluster sampling.

\section{Results}

Descriptive results: determinants of overweight

We examined overweight and its proximate, acculturation, and structural determinants by generation and ethnicity. These descriptive analyses revealed the extent to which there was apparent acculturation in these correlates of overweight that explained the differential in overweight by generation of US residence.

Structural and acculturation-related characteristics varied by ethnicity and generation (Table 2). First generation adolescents had lower income and maternal education and lived in urban areas of higher crime, higher linguistic isolation, higher ethnic dispersion, and higher minority population. Statistically smaller proportions of foreign-born Mexicans and Puerto Ricans spoke English at home. Reverse patterns were seen for Puerto Ricans on income, education, and ethnic dispersion measures; however, it must be kept in mind that there was a substantially small percentage of first generation (island-born) Puerto Ricans in the study sample.

Overweight prevalence was higher, although not statistically significant, among US-born versus foreignborn immigrants, with the exception of Mexicans who had similar overweight prevalence across generation (Table 3). In comparison, activity and inactivity varied less by generation (Table 3). Relative to US-born Mexicans, foreign-born Mexicans watched significantly less TV and videos and had fewer weekly bouts of low intensity physical activity. US-born Cubans spent more hours engaged in computer/video game use than their foreign-born counterparts.

Dietary patterns varied substantially by ethnicity and generation (Table 4). First generation Mexicans reported lower intake of cheese and fast foods, and greater intake of rice, beans, fruits, and vegetables. Foreignborn adolescents had significantly greater intake of fruits (Puerto Ricans) and vegetables (Cubans) than their native-born counterparts. More US-born, relative to foreign-born, Mexican adolescents consumed low fat foods. In general, daily breakfast and lunch intake was higher among foreign-born adolescents. 
Table 2

Structural characteristics and acculturation variables by ethnicity and generation

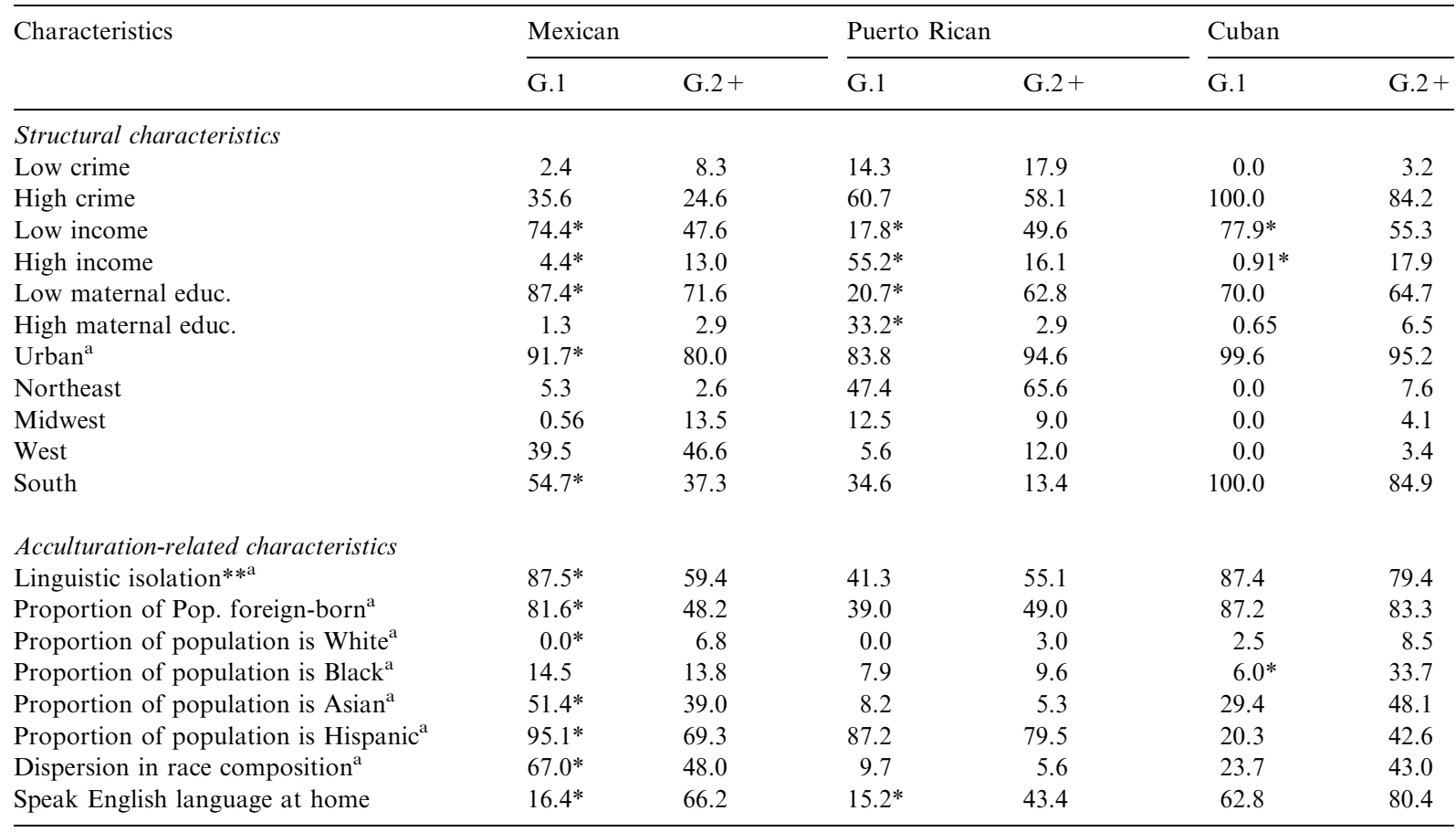

*Within ethnicity generation differences $p<0.05$.

**The Bureau of the Census defines "linguistic isolation" as a household "in which no person age 14 yr or over speaks only English and no person age $14 \mathrm{yr}$ or over who speaks a language other than English speaks English 'Very well.' All the members of a linguistically isolated household are tabulated as linguistically isolated, including members under age 14 yr who may speak only English."

${ }^{\text {a }}$ Contextual variable generated from Bureau of the Census data.

Table 3

Descriptive statistics for overweight and activity-related factors by generation of residence in US and ethnicity

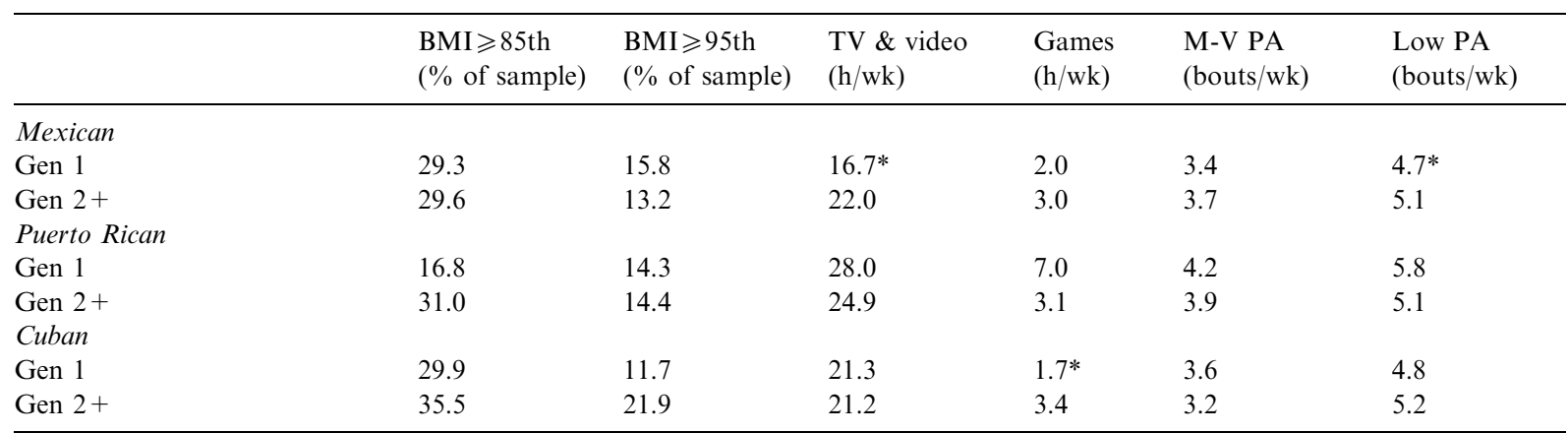

*Within ethnicity, generation differences statistically significant $p<0.05$.

Smoking patterns varied considerably for foreignversus US-born immigrants (Table 4). Statistically significant differences were found for Mexicans (total and females). In general, dietary habits were healthier and smoking rates lower for foreign-born versus USborn immigrants.
Modeling overweight status: Are generation contrasts in obesity and its determinants significant within ethnic group?

We used a series of successive logistic regression models of overweight using generation-ethnicity interaction terms and a series of important mediators 
Table 4

Percent of sample to consume foods related to acculturation and percent of sample to smoke cigarettes by ethnicity and generation

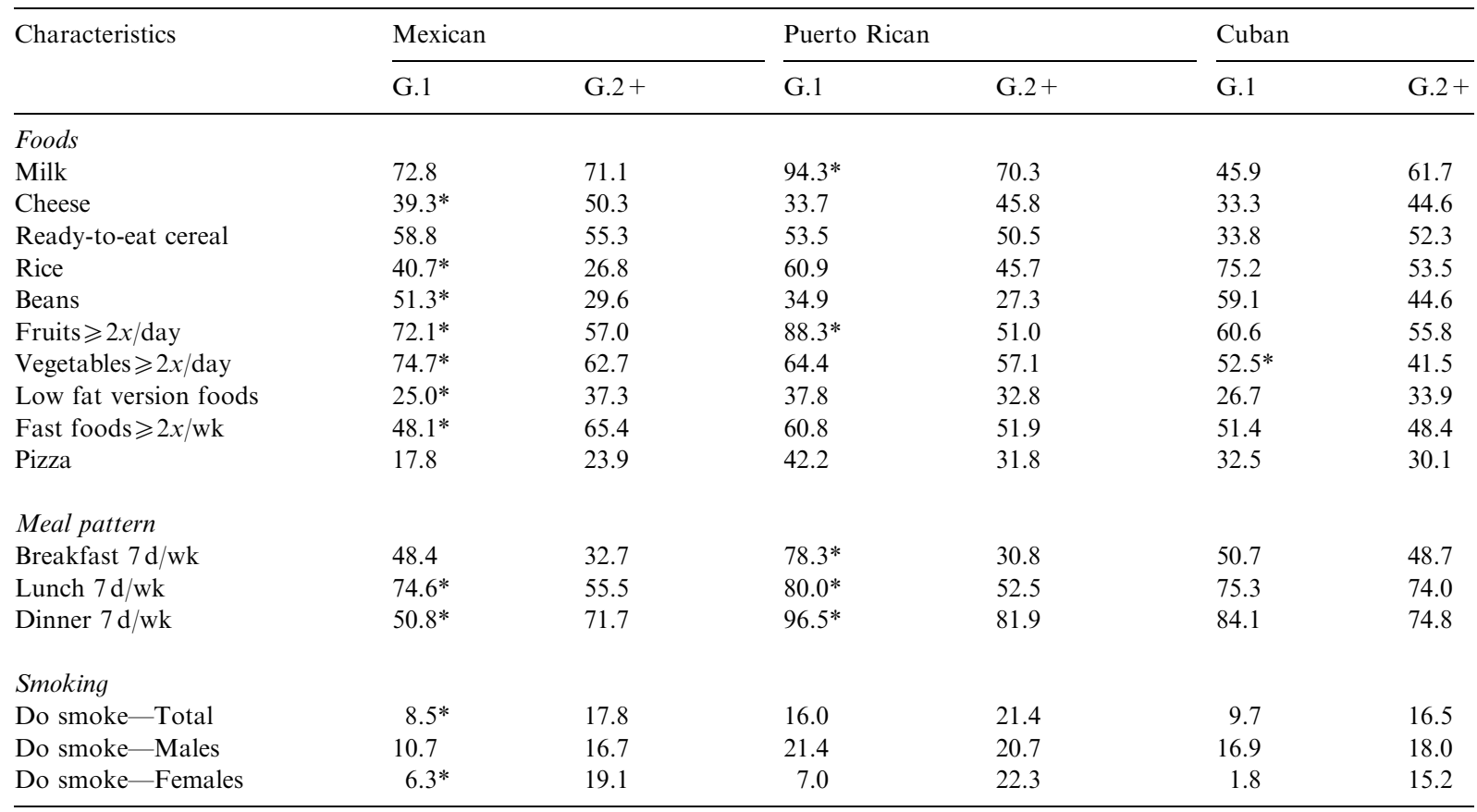

*Within-ethnicity generation differences $p<0.05$.

(coefficients and $T$ values are shown in Appendix). We used successive models to explore the separate impact of the sets of explanatory variables (e.g., acculturation factors, structural factors, proximate determinants) on overweight.

We began with a basic model of the relationship between overweight and generation-ethnicity interactions (the fundamental exogenous variables). Model 1 (Appendix) includes key controls (e.g., age, sex, and pregnancy status). Model 2, includes structural characteristics (e.g., family income, maternal education, region, and neighborhood crime), which we know place immigrant youth at greater risk for poor nutritional and activity outcomes. Model 3 includes acculturation variables (e.g., proportion of foreign-born neighbors, proportion of Hispanic, White, and Black population in neighborhood, and English language spoken at home), which either tie youth to their ethnic background and values or integrate youth into American society. Model 4 (Appendix) includes proximate determinants (e.g., physical activity, inactivity, dietary, and smoking). Model 5 (Appendix 1) includes all variables, but removes the set of acculturation characteristics.

We ran simulations and calculated predicted probabilities of overweight status using coefficients from the logistic regression models. These simulations indicate the likelihood of overweight at an assigned level of ethnicity and generation, allowing all covariates to vary by individual.

Predicted probabilities for the basic model (Model 1) are shown in Table 5. Results were similar to the unadjusted overweight prevalence data (Table 3). Overweight prevalence among US-born adolescents was substantially higher than that for foreign-born adolescents (except among Mexican-Americans).

Adding the key economic and other structural characteristics measures had minimal impact on likelihood of overweight (Model 2). Simulated probabilities of overweight remained comparable, with increased predicted overweight for first generation Puerto Ricans (Table 5). There was a slight narrowing of the effect for Puerto Ricans. Conversely, differences among Cubans increased.

We found a major shift in predicted overweight prevalence with the addition of the measures of acculturation (Model 3). When adjusted for acculturation, predicted overweight prevalence increased for all foreign-born immigrants. Generation differences in predicted overweight decreased among Cubans and Puerto Ricans, but increased among Mexicans relative to Model 2 (Table 5). None of the acculturation covariates were statistically significant; however, the total effect of the full set of acculturation measures was important. 
Predicted probabilities for overweight by generation and ethnicity*

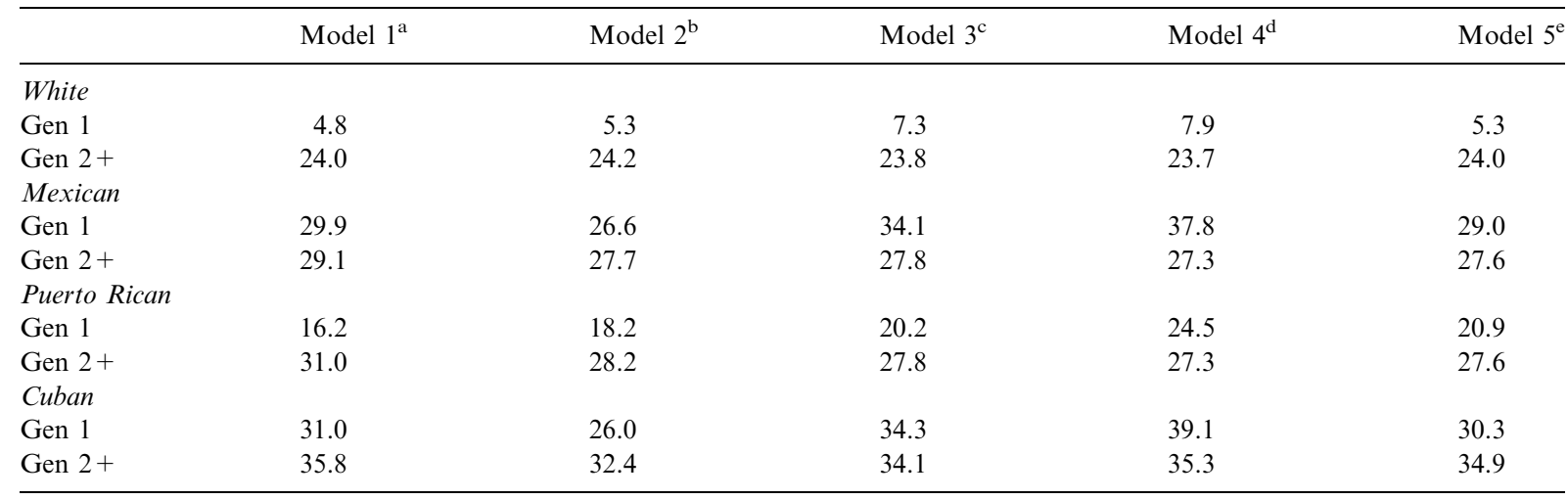

*All models correct for survey design and effects of multiple stages of cluster sampling.

${ }^{a}$ Model 1: Controls for key covariates (sex, age, pregnancy) with ethnicity, Generation 1, and ethnicity by Generation 1 interaction term.

${ }^{\mathrm{b}}$ Model 2: Adds structural characteristics (income, education, urban residence, region, neighborhood crime).

${ }^{\mathrm{c}}$ Model 3: Adds acculturation characteristics (proportion of foreign-born neighbors, population of Hispanics and Whites in neighborhood, English spoken in home, years in US).

${ }^{\mathrm{d}}$ Model 4: Adds physical activity, inactivity (baseline and 1-yr change in: TV and video viewing, video/computer games, moderatevigorous physical activity, low intensity physical activity), diet variables (consumption of: milk, cheese, ready-to-eat cereal, rice, beans, fruit, vegetables, lowfat version foods, fast foods, pizza, breakfast, lunch, dinner), and smoking.

${ }^{\mathrm{e}}$ Model 5: Removes acculturation characteristics but retains all physical activity, inactivity, diet, and smoking variables.

In Model 4, proximate overweight determinants were added (e.g., physical activity, inactivity, dietary intake, and smoking measures). In these models, the significant effects for Cubans (US- and foreign-born) and Mexicans (foreign-born) remained. Using the additional measures, some of which were themselves highly statistically significant [e.g., TV and video viewing (positive) and smoking, cereal, fast food and pizza intake, and breakfast and lunch patterns (negative)] did not dramatically alter the sign and significance of the ethnicity-generation coefficients. We found increased predicted overweight prevalence among all foreign-born Hispanics with the addition of proximate determinants into the model (Table 5). Thus, part of the explanation for increasing overweight with US residence was due to changes in the proximate overweight determinants (in particular TV and video viewing and dietary practices) with acculturation to US lifestyle.

To assess the impact of acculturation on overweight over and above the impact of proximate determinants, we removed the acculturation variables from Model 4 (results from Models 4 and 5 are shown in Appendix). Without controlling for acculturation, predicted overweight prevalence was similar to that in the model with only key covariates (Table 5). Thus, acculturation did have a major impact on overweight among all foreignborn Hispanics. In fact, across all of the models there is very little change in overweight prevalence among the
US-born adolescents, the impact is only seen for foreignborn.

\section{Discussion}

This study capitalized upon a large sample of Hispanic immigrant adolescents and detailed sociodemographic and contextual data. We investigated within-ethnicity generation differences in overweight among three important Hispanic subpopulations (Mexicans, Puerto Ricans, and Cubans). We specifically investigated the relationship between overweight, acculturation factors, structural factors, and proximate determinants in the process of acculturation to an American lifestyle. We found that acculturation and proximate factors consistently explained the lower likelihood of overweight among first generation Hispanic adolescents of all backgrounds.

\section{Descriptive findings: determinants of overweight}

Foreign-born adolescents were more likely to settle in urban areas of high crime, and with the exception of Puerto Ricans, were likely to have lower family incomes and maternal education than their US-born counterparts. Low SES has been shown to lead to higher overweight prevalence in Whites, but not Black or 
Mexican American youth (Kimm et al., 1996; Patterson et al., 1997; USDHHS, 1998). Other research shows a decrease in overweight with increasing SES among White and Hispanic, but not black, female adolescents (Gordon-Larsen, Adair, \& Popkin, 2003). These findings fill a gap in the literature. Little is known about the impact of SES on lifestyle behaviors among youth (Lowry, Kann, Collins, \& Kolbe, 1996), and much less on how acculturation mediates the SES-ethnicity-overweight relationship (Winkleby, 1997).

Foreign-born Hispanic-American adolescents had a healthier dietary pattern, consuming more rice (Mexicans), fruits (Mexicans, Puerto Ricans), and vegetables (Mexicans, Cubans) than their US-born counterparts. This is similar to findings from other studies contrasting acculturation status and dietary patterns among Hispanics (Schaffer et al., 1998; Guendelman \& Abrams, 1995; Winkleby et al., 1994; Dixon, Sundquist, \& Winkleby, 2000; Mendoza \& Dixon, 1999; Siega-Riz \& Popkin, 2001). Healthy low fat foods such as beans, tortillas and rice are a critical part of traditional (i.e., foreign-born) Hispanic cuisine.

Inactivity (e.g., TV/video and computer/video game use) and low intensity physical activity increased with generation of US residence among Mexicans and Cubans. However, differences in physical activity and inactivity patterns were not as striking, and perhaps less malleable, as those for dietary pattern. Research on this topic has shown substantially higher levels of physical activity among foreign- versus US-born Pima Indians (Esparza et al., 2000) and Mexican adults (Stern et al., 1992).

The final proximate determinant, smoking, increased dramatically for Mexican adolescents with longer US residence, and although not statistically significant, rates also increased among the other sex and ethnicity groups. Our finding is similar to what has been shown in the literature on acculturation and smoking among Hispanic adolescents (Parker, Sussman, Crippens, Elder, \& Scholl, 1998; Epstein, Botvin, \& Diaz, 1998; Dusenberry, Epstein, Botvin, \& Diaz, 1994).

There is likely to be substantial interplay between acculturation, structural, and proximate determinants in development of overweight. For example, structural factors, such as income and education may determine the level of access to an American lifestyle, with decreased physical activity opportunities and increased availability of high-fat energy-dense foods, and thus higher obesity among low SES populations. One might hypothesize that immigrants who are not able to move out from these areas and into higher SES neighborhoods are more likely to live in environments that may discourage the adoption of healthier lifestyle patterns. However, retention of traditional lifestyle patterns may buffer this relationship. For example, low SES immigrants who speak their native language and live in neighborhoods with high immigrant density (e.g., our findings for Mexican immigrants) and availability of traditional goods and services might be buffered against the adoption of American lifestyle patterns related to overweight.

\section{Does the ethnicity effect on overweight status vary by generation?}

Our multivariate results showed significant effects of ethnicity and generation on overweight after controlling for sociodemographic and acculturation factors and a range of dietary- and activity-related covariates. The predicted probabilities indicate that controlling for acculturation and proximate factors increased overweight among foreign-born adolescents, but had minimal impact for US-born adolescents. Thus, without the beneficial pattern of acculturation factors, diet, and physical activity, first generation Hispanic adolescents would have higher overweight prevalence. When we removed acculturation factors from the model (Model 5) we found that overweight decreased for the first generation adolescents; thus indicating that acculturation factors had a greater impact than proximate factors and were protective against overweight.

Although we found a protective effect of acculturation on overweight among all foreign-born Hispanic adolescents, we found that overweight prevalence was substantially higher among foreign-born versus US-born Mexicans when acculturation and proximate factors were controlled. Mexico has higher prevalence of obesity and diet-related non-communicable diseases than found in Latin America, and the Carribean (e.g., Popkin, 1998; Gonzalez-Cossio et al., 2001; Rivera et al., 2002). Dixon et al. (2000) found that nutrition profiles were similar for US-born Mexican-American women regardless of whether they spoke Spanish (less acculturated) or spoke English (more acculturated). The authors suggest that their findings, which differ from others, may be due to the difficulties in differentiating populations based on only one characteristic of acculturation without adjusting for others. Most research on this topic has been on adults, with very little published data on adolescents.

Acculturation in relation to sociodemographic, contextual, and behavioral factors

Immigrant adolescents are likely to be influenced by the "obesigenic" environment of the US, including sedentary lifestyles, large portion sizes, heavy advertising of high-fat, energy-dense foods, and mass media. Acculturation during adolescence may be intensive, given social development and the social development and the heightened influence of peers who may represent what it is to be an American adolescent. In addition, socieconomic differences in the selectivity of who 
Table 6

Correlates of overweight for Hispanic immigrants to the US ${ }^{\mathrm{a}}$

\begin{tabular}{|c|c|c|c|c|c|c|}
\hline Variables & \multicolumn{2}{|c|}{ Model 1 results $^{\mathrm{b}}$} & \multicolumn{2}{|c|}{ Model 4 results $^{\mathrm{c}}$} & \multicolumn{2}{|c|}{ Model 5 results $^{\mathrm{d}}$} \\
\hline Gen 1 & -1.84 & $(-3.38)^{* *}$ & -1.32 & $(-2.31)^{*}$ & -1.77 & $(-3.46)^{* *}$ \\
\hline Mex. \& Gen 1 & 1.88 & $(2.96)^{* *}$ & 1.83 & $(2.94)^{* *}$ & 1.85 & $(3.00)^{* *}$ \\
\hline PR ethnicity & 0.35 & $(1.76)$ & 0.20 & $(0.88)$ & 0.20 & $(0.89)$ \\
\hline PR \& Gen 1 & 1.00 & $(1.02)$ & 1.17 & $(1.20)$ & 1.39 & $(1.44)$ \\
\hline Sex & -0.22 & $(-3.41)^{* *}$ & -0.31 & $(-4.34)^{* *}$ & -0.31 & $(-4.33)^{* *}$ \\
\hline Age 16,17 yr & -0.21 & $(-2.43)^{*}$ & -0.23 & $(-3.15)^{* *}$ & -0.23 & $(-3.15)^{* *}$ \\
\hline Age $18+$ yr & -0.34 & $(-3.16)^{* *}$ & -0.38 & $(-3.50)^{* *}$ & -0.38 & $(-3.48)^{* *}$ \\
\hline Pregnancy & 0.62 & $(1.91)$ & 0.61 & $(1.90)^{*}$ & 0.61 & $(1.93)$ \\
\hline Low income & & & 0.10 & (1.09) & 0.10 & (1.09) \\
\hline High income & & & -0.10 & $(-1.10)$ & -0.10 & $(-1.12)$ \\
\hline Northeast region & & & 0.26 & $(2.18)$ & 0.25 & $(2.17)^{*}$ \\
\hline Low neighborhood crime & & & 0.09 & $(1.20)$ & 0.05 & $(0.58)$ \\
\hline High neighborhood crime & & & -0.02 & $(-0.16)$ & -0.02 & $(-0.12)$ \\
\hline Smoker & & & -0.16 & $(-2.07)^{*}$ & -0.16 & $(-2.01)$ \\
\hline TV/video $(>26 \mathrm{~h} /$ wk $)$ & & & 0.41 & $(4.66)^{* *}$ & 0.41 & $(4.68)^{* *}$ \\
\hline 1-yr TV/video $(\geqslant 7 \mathrm{~h} / \mathrm{wk})$ & & & 0.15 & $(2.00)^{*}$ & 0.15 & $\left(2.01^{*}\right)$ \\
\hline IA games $(>1 \mathrm{~h} / \mathrm{wk})$ & & & 0.04 & $(0.53)$ & 0.04 & $(0.51)$ \\
\hline 1-yr games $(\geqslant 1 \mathrm{~h} / \mathrm{wk})$ & & & 0.05 & $(0.61)$ & 0.05 & $(0.65)$ \\
\hline M-V PA (> 4 bouts/wk) & & & -0.11 & $(-1.32)$ & -0.11 & $(-1.33)$ \\
\hline 1-yr. M-V PA $(\geqslant 1 \mathrm{~b} / \mathrm{wk})$ & & & 0.07 & $(0.93)$ & 0.07 & $(0.96)$ \\
\hline Low PA ( $>5$ bouts/wk) & & & 0.06 & $(0.71)$ & 0.06 & $(0.72)$ \\
\hline 1-yr low PA $(\geqslant 1 \mathrm{~b} / w k)$ & & & 0.12 & $(1.61)$ & 0.12 & $(1.60)$ \\
\hline Milk intake & & & 0.11 & $(1.36)$ & 0.11 & $(1.34)$ \\
\hline Pizza intake & & & -0.31 & $(-3.68) * *$ & -0.31 & $(-3.71) * *$ \\
\hline Breakfast intake (7d/wk) & & & -0.43 & $(-4.76)^{* *}$ & -0.43 & $(-4.78)^{* *}$ \\
\hline Lunch intake $(7 \mathrm{~d} / \mathrm{wk})$ & & & -0.19 & $(-2.37)^{* *}$ & -0.18 & $(-2.32)^{*}$ \\
\hline Dinner intake $(7 \mathrm{~d} / \mathrm{wk})$ & & & 0.05 & $(0.71)$ & 0.05 & $(0.70)$ \\
\hline$\%$ Foreign-born neighbors & & & -0.06 & $(-0.37)$ & & \\
\hline$\%$ White population & & & -0.10 & $(-0.92)$ & & \\
\hline$\%$ Hispanic population & & & 0.05 & $(0.43)$ & & \\
\hline $0-5 \mathrm{yr}$ in US & & & -0.73 & $(-1.74)$ & & \\
\hline $6-10 \mathrm{yr}$ in US & & & -0.35 & $(-0.68)$ & & \\
\hline Speak English at home & & & 0.04 & $(0.27)$ & & \\
\hline
\end{tabular}

$* p<0.05$

$* * p<0.01$

${ }^{a}$ Model corrects for survey design effects of multiple stages of cluster sampling.

${ }^{\mathrm{b}}$ Model 1: Controls for key covariates (sex, age, pregnancy) with Hispanic, Generation 1, and Hispanic by Generation 1 interaction term

${ }^{\mathrm{c}}$ Model 4: Adds structural characteristics (income, education, urban residence, region, neighborhood crime), acculturation characteristics (proportion of foreign-born neighbors, population of Hispanics, and Whites in neighborhood, English spoken in home, years in US), and activity and diet variables [physical activity, inactivity (baseline and 1-yr change in: TV and video viewing, video/ computer games, moderate-vigorous physical activity, low intensity physical activity), and diet variables (consumption of: milk, cheese, ready-to-eat cereal, rice, beans, fruit, vegetables, lowfat version foods, fast foods, pizza, breakfast, lunch, dinner)] and smoking.

${ }^{\mathrm{d}}$ Model 5. Identical to Model 4, but removes the acculturation characteristics (proportion of foreign-born neighbors, population of Hispanics and Whites in neighborhood, English spoken in home, years in US). 
chooses to immigrate to the US may also influence the effects of acculturation on overweight and activity patterns.

Our results suggest a rapid acculturation of a series of obesity-related behaviors with first to subsequent generation of US residence. In particular, we found markedly higher rates of overweight in second generation immigrants, with the exception of Mexican-Americans. We found important sociodemographic and contextual structural differences between US- and foreign-born adolescents that are likely to underlie the large increase in overweight prevalence between the first and subsequent generation of US residence. The incorporation of a full set of measures of acculturation allowed us to reduce the generation effect in all groups, except Mexican-Americans. Indeed, acculturation had a major impact on overweight among all foreign-born Hispanics.

\section{Conclusion}

We have demonstrated the importance of structural, acculturation, and proximate determinants in the increase in overweight with generation of US residence. These results suggest that there are several avenues for prevention of overweight through modifications in dietary and physical activity patterns. In addition, this paper has shown that there are specific patterns of acculturation and structural factors that may encourage the development of overweight and are thus important in delineating groups at risk for overweight. Given the substantial increase in overweight and the considerable morbidity and mortality associated with overweight, it is imperative to determine the factors most associated with the marked increase in overweight over generation of residence among US immigrants.

\section{Acknowledgements}

Funds for the research reported in this article were provided by the National Institute of Child Health and Human Development (R01-HD39183). This paper is based on data from the Add Health project, a program project designed by J. Richard Udry (PI) and Peter Bearman, and funded by grant P01-HD31921 (and P01HD31921-01) from the National Institute of Child Health and Human Development to the Carolina Population Center, University of North Carolina at Chapel Hill. The authors would like to thank Sanders Korenman for his helpful comments on an earlier draft of this paper. We also thank comments from the participants to the Carolina Population Center Seminar Series. In addition, we thank Ms. Frances Dancy for her helpful administrative assistance, Kim Chantala, and
David Guilkey for help with statistical modeling advice, Tom Swasey for graphics assistance, and Samara Nielsen for help with programming simulations.

\section{Appendix}

See Table 6.

\section{References}

Andersen, R. E., Crespo, C. L., Bartlett, S. J., Cheskin, L. J., \& Pratt, M. (1998). Relationship of physical activity and television watching with body weight and level of fatness among children: Results from the third national health and nutrition examination survey. Journal of the American Medical Association, 279, 938-942.

Baranowski, T. (1988). Validity and reliability of self-report measures of physical activity: An information processing perspective. Research Quarterly in Exercise and Sport, 59, 314-327.

Camp, D. E., Klesges, R. C., \& Relyea, G. (1993). The relationship between body weight concerns and adolescent smoking. Health Psychology, 12(1), 24-32.

Centers for Disease Control and Prevention. (2000). Centers for Disease Control and Prevention/National Center for Health Statistics. United States Growth Curves. Hyattsville, MD: US Department of Health and Human Services: Centers for Disease Control and Prevention.

Committee on the Health and Adjustment of Immigrant Children and Families (1998). From generation to generation: the health and well-being of children in immigrant families (pp. 314). Washington DC: National Academy Press.

Dietz, W. H. (1994). Critical periods in childhood for the development of obesity. American Journal of Clinical Nutrition, 59, 955-959.

Dixon, L. B., Sundquist, J., \& Winkleby, M. (2000). Differences in energy, nutrient, and food intakes in a US sample of Mexican-American women and men: Findings from the third national health and nutrition examination survey, 1988-1994. American Journal of Epidemiology, 152, 548557.

Dusenberry, L., Epstein, J. A., Botvin, C. G., \& Diaz, T. (1994). The relationship between language spoken and smoking among Hispanic-Latino youth in New York City. Public Health Reports, 109, 421-427.

Epstein, J. A., Botvin, G. J., \& Diaz, T. (1998). Linguistic acculturation and gender effects on smoking among Hispanic youth. Preventive Medicine, 27, 583-589.

Epstein, L. H., Valoski, A. M., Vara, L. S., McCurley, J., Wisniewski, L., \& Kalarchian, M. A., et al. (1995). Effects of decreasing sedentary behavior and increasing activity on weight change in obese children. Health Psychology, 14, 109-115.

Epstein, L. H., Saelens, B. E., Myers, M. D., \& Vito, D. (1997). Effects of decreasing sedentary behaviors on activity choice in obese children. Health Psychology, 16, 107-113. 
Esparza, J., Fox, C., Harper, I. T., Bennet, P. H., Schulz, L. O., \& Valencia, M. E., et al. (2000). Daily energy expenditure in Mexican and USA Pima Indians: Low physical activity as a possible cause of obesity. International Journal of Obesity, 24, 55-59.

Flegal, K. M., Troiano, R. P., Pamuk, E. R., Kuczmarski, R. J., \& Campbell, S. M. (1995). The influence of smoking cessation on the prevalence of overweight in the United States. New England Journal of Medicine, 333, 1165-1170.

French, S. A., Perry, C. P, Leon, G. R., \& Fulkerson, J. A. (1994). Weight concerns, dieting behavior and smoking initiation in adolescents: A prospective epidemiologic study. American Journal of Public Health, 84, 1818-1820.

French, S. A., Story, M., Downes, B., Resnick, M. D., \& Blum, R. W. (1995). Frequent dieting among adolescents: Psychosocial and health behavior correlates. American Journal of Public Health, 85(5), 695-701.

Gonzalez-Cossio, T., Rivera, J., Shamah, T., Barquera, S., Hernandez, B., Sepulveda, J. (2001). Obesity in Mexico: A growing epidemic. Vienna, Austria: International Congress of Nutrition, August 26-30.

Gordon, M. M. (1964). Assimilation in American life: The role of race, religion, and national origin. New York: Oxford University Press.

Gordon-Larsen, P., Adair, L., \& Popkin, B. M. (2003). The relationship between ethnicity, socioeconomic factors and overweight: the National Longitudinal Study of Adolescent Health. Obesity Research, 11, 121-129.

Gordon-Larsen, P., McMurray, R. G., \& Popkin, B. M. (1999). Adolescent physical activity and inactivity vary by ethnicity: The national longitudinal study of adolescent health. Journal of Pediatrics, 135, 301-306.

Gortmaker, S. L., Sobal, A. M., Peterson, K., Colditz, C. A., \& Dietz, W. H. (1996). Television viewing as a cause of increasing obesity among children in the United States. Archives of Pediatric and Adolescent Medicine, 150, 536-562.

Guendelman, S. (1988). Sociocultural factors in Hispanic pregnancy outcome. In C. J. Morton, \& R. G. Hirsch (Eds.), Developing public health social work programs to prevent low birthweight and infant morality: High risk populations and outreach (pp. 31-39). ). Berkeley, CA: Maternal and Child Health Program, School of Public Health University of California at Berkeley.

Guendelman, S., \& Abrams, B. (1995). Dietary intake among Mexican-American women: Generational differences and a comparison with White non-Hispanic women. American Journal of Public Health, 85, 20-25.

Harris, K. M. (1998). The health status and risk behavior of adolescents in immigrant families. In D. Hernandez (Ed.), The health and adjustment of immigrant children and families. Washington, DC: National Academy Press.

Harris, K. M. (1999a). The health status and risk behavior of adolescents in immigrant families. In D. Hernandez (Ed.), Children of immigrants: Health, adjustment, and public assistance (pp. 286-347). Washington, DC: National Academy Press.

Harris, K. M. (1999b). Health risk behavior among adolescents in immigrant families. Paper presented at the second biannual meeting of the urban seminar series on children's health and safety entitled successful youth in high-risk environments. Harvard University, December 2-3, 1999.
Hernandez, D. J. (1993). America's children: Resources from family, government, and the economy. New York: Russell Sage Foundation.

Hernandez, D. J., \& Charney, E. (1998). Health status and adjustment. In D. J. Hernandez, \& E. Charney (Eds.), From generation to generation: the health and well-being of children in immigrant families. Washington, DC: National Academy Press.

Himes, J. H., \& Dietz, W. H. (1994). Guidelines for overweight in adolescent preventive services: Recommendations from an expert committee. American Journal of Clinical Nutrition, 59, 307-316.

Hirschman, C. (1996). Studying immigrant adaptation from the 1990 population census: From generational comparisons to the process of becoming American. In A. Portes (Ed.), The new second generation (pp. 54-81). New York: Russell Sage Foundation.

Jasso, G., \& Rosenzweig, M. R. (1990). The new chosen people: Immigrants to the United States. New York: Russell Sage Foundation.

Kimm, S. Y., Obarzanek, E., Barton, B. A., Aston, C. E., Similo, S. L., \& Morrison, J. A., et al. (1996). Race, socioeconomic status, and obesity in 9- to10-year-old girls: The NHLBI growth and health study. Annals of Epidemiology, 6, 266-275.

Lieberson, S. (1980). A piece of the pie: Blacks and White immigrants since 1880. Berkeley: University of California Press.

Lowry, R., Kann, L., Collins, J. L., \& Kolbe, L. J. (1996). The effect of socioeconomic status on chronic disease risk behaviors among US adolescents. Journal of the American Medical Association, 276, 792-797.

Massey, D. S. (1996). The age of extremes: Concentrated affluence and poverty in the twenty-first century. Demography, 33, 395-412.

Mendoza, F. S., \& Dixon, L. B. (1999). The health and nutritional status of immigrant Hispanic children: analyses of the Hispanic Health and Nutrition Examination Survey. In D. J. Hernandez (Ed.), Children of immigrants: health, adjustment and public assistance. Washington, DC: National Academy Press.

Park, R. E. (1950). Race and culture. Glencoe, IL: Free Press.

Parker, V., Sussman, S., Crippens, D., Elder, P., \& Scholl, D. (1998). The relation of ethnic identification with cigarette smoking among US Urban African American and Latino youth: A pilot study. Ethnicity and Health, 3, 135-143.

Pate, R. R., Heath, G. W., Dowda, M., \& Trost, S. G. (1996). Associations between physical activity and other health behaviors in a representative sample of US adolescents. American Journal of Public Health, 86, 1577-1581.

Patterson, M. L., Stern, S., Crawford, P. B., McMahon, R. P., Similo, S. L., \& Schreiber, G. B., et al. (1997). Sociodemographic factors and obesity in preadolescent black and white girls: NHLBI's growth and health study. Journal of the National Medical Association, 89, 594-600.

Popkin, B. M. (1998). The nutrition transition and its health implications in lower income countries. Public Health Nutrition, 1, 5-21.

Popkin, B. M., \& Udry, J. R. (1998). Adolescent obesity increases significantly for second and third generation US immigrants: The national longitudinal study of adolescent health. Journal of Nutrition, 128, 701-706. 
Portes, A. (1996). The new second generation. New York: Russell Sage Foundation.

Portes, A., \& Zhou, M. (1993). The new second generation: Segmented assimilation and its variants. Annals of the American Academy of Political and Social Sciences, 530, 74-96.

Raitakari, O. T., Porkka, K. V. K, Taimela, S., Telama, R., Rasanen, L., \& Viikari, J. S. A. (1994). Effects of persistent physical activity and inactivity on coronary risk factors in children and young adults: The cardiovascular risk in young Finns study. American Journal of Epidemiology, 140, 195-205.

Rivera, JA., Barquera, S., Campirano, F., Campos, I., Safdie, M., \& Tovar, V. (2002). Epidemiological and nutritional transition in Mexico: Rapid increase of non-communicable chronic diseases and obesity. Public Health Nutrition, 5(1A), $113-122$

Sallis, J. F., Buono, M. J., Roby, J. J., Micale, F. G., \& Nelson, J. A. (1993). Seven-day recall and other physical activity self-reports in children and adolescents. Medicine Science Sport and Exercise, 25, 99-108.

Schaffer, D. M., Velie, E. M., Shaw, G. M., \& Todoroff, K. P. (1998). Energy and nutrient intakes and health practices of Latinas and White non-Latinas in the 3 months before pregnancy. Journal of the American Dietetic Association, 98, 876-884.

Scribner, R. (1996). Editorial: Paradox as health outcomes of Mexican Americans. American Journal of Public Health, 86, 303-305.

Scribner, R., \& Dwyer, J. H. (1989). Acculturation and low birthweight among Latinos in the Hispanic HANES. American Journal of Public Health, 79, 1263-1267.

Serdula, M. K., Ivery, D., Coates, J. R., Freedman, D. S., Williamson, D. F., \& Byers, T. (1993). Do obese children become obese adults? A review of the literature. Preventive Medicine, 22, 167-177.

Siega-Riz, A. M., \& Popkin, B. M. (2001). Dietary trends among low socio-economic status women of childbearing ages in the US from 1977-95: A comparison among ethnic groups. Journal of the American Medical Women's Association, 44, 44-48.
Siervogel, R. M., Roche, A. F., Guo, S. M., Mukherjee, D., \& Chumlea, W. C. (1991). Patterns of change in weight/ stature $^{2}$ from 2 to 18 years: Findings from long-term serial data for children in the Fels longitudinal growth study. International Journal of Obesity, 15, 479-485.

StataCorp. (1999). Stata statistical software: release 6.0. College Station, TX: Stata Corporation.

Stern, M. P., Gonzalez, C., Mitchell, B. D., Villalpondo, E., Haffner, S. M., \& Hazuda, H. P. (1992). Genetic and environmental determinants of type II diabetes in Mexico City and San Antonio. Diabetes, 41(4), 484-492.

Sundquist, J., \& Winkleby, M. A. (1999). Cardiovascular risk factors in Mexican-American adults: A transcultural analysis of NHANES III, 1988-1994. American Journal of Public Health, 89, 723-730.

US Department of Health and Human Services (1996). Physical activity and health: A report of the surgeon general. Atlanta, GA: USDHHS, Centers for Disease Control and Prevention, National Center for Chronic Disease Prevention and Health Promotion.

US Department of Health and Human Services (1998). Health, United States, 1998. Hyattsville MD: National Center for Health Statistics.

WHO Expert Committee (1995). Physical status: The use and interpretation of anthropometry. WHO Technical Report Series 854. Geneva, Switzerland: World Health Organization.

Winkleby, M. A. (1997). Accelerating cardiovascular risk factor change in ethnic minority and low socioeconomic groups. Annals of Epidemiology, 7(Suppl.), S96-S103.

Winkleby, M. A., Albright, C. L., Howard-Pitney, B., Lin, J., \& Fortmann, S. P. (1994). Hispanic/white differences in dietary fat intake among low educated adults and children. Preventive Medicine, 23, 465-473.

Wolfe, B. L. (1994). Reform of health care for the nonelderly poor. In S. H. Danziger, G. D. Sandefur, \& D. H. Weinberg (Eds.), Confronting poverty: Prescriptions for change (pp. 253-288). New York: Russell Sage Foundation.

Zhou, M. (1997). Growing up American: The challenge confronting immigrant children and children of immigrants. Annual Review of Sociology, 23, 63-95. 